Enclaves. Revista de Literatura, Música y Artes Escénicas, n. ${ }^{\circ}$ 1, 2021, pp. 6-17. e-ISSN 2792-7350

Inés María Luna, «El idealismo romántico en la cultura flamenca:

\title{
EL IDEALISMO ROMÁNTICO EN LA CULTURA FLAMENCA: MITO, MODERNIDAD Y TRISTEZA
}

\author{
Inés María Luna \\ I.E.S. Murillo (Sevilla)-Junta de Andalucía
}

Fecha de recepción: 03/11/2020

Fecha de aceptación: 09/05/2021

\section{Resumen}

Nadie hablaría hoy de flamenco como de un arte puro. Sin embargo, esta disciplina no puede comprenderse si no atendemos a lo que ha sido, en distintos momentos de su construcción artística, la búsqueda constante de un ideal. Defender su pureza ha significado, en muchas ocasiones, no hablar estrictamente de un arte sin mezclas, sino la defensa de un ideal humanístico. Olvidarnos de este anhelo de cultura idealizada y de sus principales representantes significa olvidarnos de la naturaleza romántica de esta manifestación artística y de aquellos que han ido, a lo largo de los años, conformando su dimensión estética.

Cuando han sido superados muchos de los postulados de la flamencología tradicional, nos planteamos la necesidad de revisar de manera crítica la importancia del mito. Consideramos desde una nueva perspectiva, sobre todo desde la revolución idealista que inunda el arte y la literatura de finales del XIX, cómo la búsqueda constante de un ideal ha enriquecido y dignificado la realidad flamenca y la ha convertido en modelo de cultura idealizada, sin que ello haya significado el alejamiento de los escenarios ni la pérdida de contacto con otras disciplinas artísticas.

Palabras clave: Flamenco, modernidad, Romanticismo, tristeza, idealismo, cultura popular.

\section{ROMANTIC IDEALISM IN FLAMENCO CULTURE: MYTH, MODERNITY AND SADNESS}

\begin{abstract}
Nobody would speak of flamenco today as a pure art. However, this discipline can not be understood, if we do not pay attention to what the constant search for an ideal has been at different moments of its artistic construction. Defending its purity has meant on many occasions, not speaking strictly of an art without mixtures, but the defense of a humanistic ideal. Forgetting this longing for idealized culture and its main representatives means forgetting the romantic nature of this artistic manifestation and those who have been shaping its aesthetic dimension over the years.

When many of the postulates of traditional flamencology have been overcome, we consider the need to critically review the importance of myth. We consider from a new
\end{abstract}


Enclaves. Revista de Literatura, Música y Artes Escénicas, n. ${ }^{\circ}$ 1, 2021, pp. 6-17. e-ISSN 2792-7350

Inés María Luna, «El idealismo romántico en la cultura flamenca: mito, modernidad y tristeza», https://dx.doi.org/10.12795/enclaves.2021.i01.02

perspective, especially from the idealist revolution that inundates art and literature at the end of the 19th century, how the constant search for an ideal has enriched and dignified flamenco reality and has made it a model of idealized culture, without this having meant distancing oneself from the stage or losing contact with other artistic disciplines.

Keywords: Flamenco, Modernity, Romanticism, Sadness, Idealism, Popular culture.

\section{Sumario}

1. El flamenco como arte de la modernidad.............................................

2. La consolidación del mito flamenco..............................................

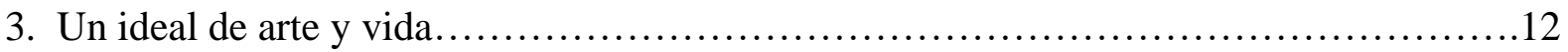

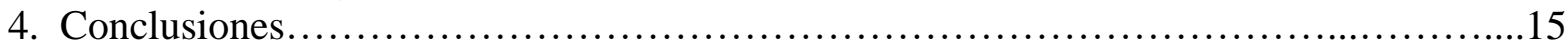

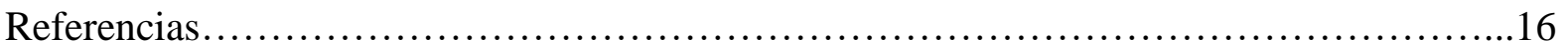

\section{El flamenco como arte de la modernidad}

Nunca ha mantenido el arte una relación tan difícil con su tiempo como ocurre a partir del Romanticismo. Y nunca se ha llegado a una voluntad de independencia como la que defienden los escritores de principios del siglo XX. Es necesario definir la realidad artística por vez primera en función de la libertad. El arte debe ser un arte libre, alejado de los principios de utilidad y no sometido a los criterios comerciales que dominan el mundo. Es un cuestionamiento del sentido artístico que adquiere un carácter primordial en la cultura del siglo XX y que sigue siendo imprescindible en nuestros días.

En este contexto de salvación por el arte, la música adquiere un protagonismo extraordinario. Se convierte en el arte por excelencia, en el objeto de la reflexión filosófica, como ocurre plenamente en Nietzsche y en Schopenhauer. ${ }^{1}$ Es la manifestación sobre la que se proyectan las aspiraciones estéticas más propias de la época: el deseo de un arte total, unido a la poesía, con vocación de humanismo, redención y trascendencia. Nos dice Fubini de manera muy elocuente: «Buena parte del pensamiento estético musical desde la mitad del XVIII hasta la crisis del Romanticismo —o sea, durante más de un siglo—, aparece recorrido, como por un hilo rojo, por el concepto de alienación del hombre a causa de la civilización y de su redención o aspiración a la redención por medio de la música» (21). Así, el Romanticismo recupera en los tiempos modernos su carácter sagrado, la vocación consoladora que, como nos explica Ramón Andrés, se le atribuye a la música desde la antigüedad. $^{2}$

Sin duda alguna, estos principios alcanzan una gran relevancia en el nacimiento del flamenco. Se pone de relieve desde el inicio, como en otras músicas populares de naturaleza romántica, ${ }^{3}$ la relación conflictiva del arte con la modernidad. También en el flamenco se muestra la predisposición filosófica que ha adquirido la música, la voluntad de recuperación de una cultura perdida que se opone de manera absoluta al arte concebido como evasión y entretenimiento.

Como es sabido, la estética flamenca va a ser conformada principalmente por los artistas románticos y modernistas, sobre todo por los creadores más relacionados con el fin de

\footnotetext{
${ }^{1}$ Recuérdese El nacimiento de la tragedia o El mundo como voluntad y representación.

${ }^{2}$ Muy valiosa resulta la publicación reciente de su obra Filosofía y consuelo de la música.

${ }^{3}$ Véase, a propósito del fado, el artículo de Mendonça.
} 
Enclaves. Revista de Literatura, Música y Artes Escénicas, n. ${ }^{\circ}$ 1, 2021, pp. 6-17. e-ISSN 2792-7350

Inés María Luna, «El idealismo romántico en la cultura flamenca: mito, modernidad y tristeza», https://dx.doi.org/10.12795/enclaves.2021.101.02

siglo. Porque no olvidemos que nuestro romanticismo es un romanticismo tardío, que muchos críticos identifican con el modernismo. En este sentido, se configura una estética que no podemos desligar del descubrimiento romántico de lo popular, ni de la nueva sensibilidad artística que la revolución romántica trae consigo. Nos referimos a una intensa estilización de lo popular que se realiza sobre todo a partir de la tristeza. Algunos poetas, músicos y escritores, vinculados especialmente con el idealismo krausista, serán fundamentales en la creación de esta nueva estética y en la creación de esta nueva cultura, que se extiende a lo largo del siglo XX y que será eminentemente literaria.

Ocurre que esta voluntad idealista del Romanticismo se une en nuestro país a la existencia de una importante tradición de la tristeza. Es necesario recordar que desde mediados del siglo XVI se considera a los españoles como los difusores de la melancolía en Europa. Las distintas manifestaciones artísticas, como ponen de relieve los autores de Saturno y la melancolía, nos inclinan a ver la España de los Siglos de Oro como expresión del realismo, la melancolía y el desengaño. Existe un interés por esta tendencia del alma que está muy presente en los tratados de algunos humanistas de la época. Resultan, por ejemplo, muy elocuentes y evocadoras las palabras de Pedro de Mercado, que veía el humor melancólico, en su obra Diálogos de filosofía natural y moral, como «un pelear con el duende» (Bolaños 24). Se trata de una concepción de la cultura que, aunque muy significativa en toda Europa, adquiere entre nosotros una dimensión exaltada. Se conforma literariamente en las voces de escritores como Miguel de Cervantes o Juan Huarte de San Juan, en este hilo melancólico que une el Examen de ingenios con la obra universal cervantina; culmina en Baltasar Gracián y en las expresiones artísticas del pesimismo barroco (Bartra 227-266; Pujante 155-174); y no desaparece en el XVIII, sino que perdura, como un substrato colectivo, en los géneros más populares de nuestro teatro (Pujante 198). Esta doble voluntad, la que une ideal romántico con una tradición española de la melancolía, será muy enriquecedora en la creación de una primera literatura flamenca.

Nada habría sido posible si el Romanticismo no hubiese contemplado la poesía popular como la verdadera manifestación poética. A Gustavo Adolfo Bécquer le debemos la identificación de esta expresión popular con los cantos andaluces y la primera consideración de estos cantos como expresión existencial y de consuelo, una mirada estilizada de lo popular que lleva a cabo la poesía simbolista, de extraordinaria trascendencia en el nacimiento de la poesía flamenca y en la renovación de la lírica española. Esta actitud pone de relieve la voluntad de seleccionar determinados rasgos, con una inclinación hacia los cantos particularmente graves y tristes. Es una perspectiva que muestra la íntima ligazón con nuestra tradición cultural de la melancolía.

Será Antonio Machado y Álvarez, en el contexto de la escuela folclorista sevillana, especialmente en la Colección de cantes flamencos, quien elabore este tratamiento intimista de lo popular y quien desarrolle este imaginario cultural desde una perspectiva claramente romántica. Como hemos tratado en otros textos (Luna "El flamenco como expresión de lo sublime"), a pesar de las contradicciones que la crítica ha señalado, la obra de Demófilo se halla en sintonía con los presupuestos culturales del arte en la modernidad. En este sentido, el flamenco se nos muestra como salvaguarda de una cultura que se pierde. Demófilo nos ofrece la imagen de una cultura idealizada, que él identifica sobre todo con lo gitano. Pero no solo nos ofrece una imagen idealizada del cantaor, sino también del público. Acorde con unos presupuestos krausistas que insisten continuamente en la importancia de un arte libre, a Demófilo le interesa resaltar, en este público abigarrado que asiste a los cafés, la importancia del hombre sensible, de aquel que, reconociendo la belleza del dolor, es capaz de convertirse en minoría, una reivindicación de la dignidad popular, heredada más tarde por Antonio 
Enclaves. Revista de Literatura, Música y Artes Escénicas, n. ${ }^{\circ}$ 1, 2021, pp. 6-17. e-ISSN 2792-7350

Inés María Luna, «El idealismo romántico en la cultura flamenca: mito, modernidad y tristeza», https://dx.doi.org/10.12795/enclaves.2021.101.02

Machado y Juan Ramón Jiménez, que ha condicionado durante décadas la manera de acercarse al flamenco. Nos ofrece, a través de sus reflexiones teóricas y de una selección muy certera de coplas, una expresión de la pureza que no responde en muchos aspectos a una verdad histórica, pero que crea una realidad estética que hasta entonces no existía en la literatura flamenca y que se une a las inquietudes de la crisis del arte a finales del XIX. Comienza la concepción del flamenco como salvación y refugio de la cultura popular.

A partir de esta unión de música y poesía que es el cante flamenco, se realiza la búsqueda revolucionaria de una cultura perdida. No resulta extraño que esta búsqueda tenga lugar especialmente a través de la seguiriya, del estilo más relacionado con la expresión de la tragedia. Se quiere salvar una tradición, pero no desde una óptica costumbrista, sino insistiendo en un arte individual y existencial. Este sentimiento se convierte en su obra en una idealización constante del gitanismo. Porque lo gitano, símbolo de exotismo y rebeldía, viene a asociarse a finales de siglo sobre todo con la expresión de la tristeza. Es cierto, como dice Steingress, que confunde «el gitanismo como postura artística con la realidad del mundo gitano de su época» (127), pero no se ha destacado de manera suficiente la relevancia de Demófilo en esta idealización primera del gitanismo, en la configuración artística del gitano como héroe trágico, un mito que tanta trascendencia tendrá en la cultura y en el arte del siglo $\mathrm{XX}$.

Aunque es Demófilo quien conforma este imaginario cultural del flamenco, existe un contexto de reinterpretación de lo andaluz desde la tristeza que está formado por músicos, poetas o eruditos como Francisco Rodríguez Marín, Benito Mas y Prat, Joaquín Turina o Alejandro Guichot y Sierra. Cada autor lo manifiesta de manera independiente, pero encontramos en todos ellos, muy influidos por el pensamiento krausista, una voluntad de estilización de lo popular como voluntad de creación de un arte libre. Según Turina, se debe imitar y traducir en la música «el ambiente de alegría triste de la región andaluza, la melancolía e indiferencia que forma el carácter andaluz» (16). En esta tendencia también situamos al Rubén Darío de Tristeza andaluza, quien contribuye a la idealización del flamenco al considerar la voz poética de Juan Ramón Jiménez en Arias tristes como expresión moderna y personal de una cultura andaluza de la tristeza. Las palabras de Darío son muy significativas de este proceso de universalización y modernidad que está adquiriendo la cultura flamenca, que llegará a su culminación en Federico García Lorca.

La voluntad idealizadora que convierte al flamenco en regenerador del arte y de la cultura entra en contradicción en estos años con su concepción como realidad comercial. Es una crisis que se manifiesta como rechazo del propio término «Flamenco», y que se manifiesta también como rechazo de un género musical y escénico, muy ligado al andalucismo costumbrista, que a finales del XIX ya es denominado como «Cuplé». Comienza un interesante distanciamiento de flamenco y canción orquestada, que, aunque realmente solo sea un distanciamiento intelectual, será muy fructífero en la configuración estética del flamenco. Dicha estética va a constituirse desde ahora en virtud de una oposición constante a la canción orquestada. Mientras que estos cantes comienzan a ser considerados como custodia de la cultura popular, el cuplé, por el contrario, es contemplado en muchos autores como expresión de decadencia.

\section{La consolidación del mito flamenco}

Siguiendo el camino iniciado por el modernismo, influido también por los principios institucionistas, es Federico García Lorca quien consolida el mito de lo flamenco en este contexto de crisis de la cultura popular en la cultura moderna. Aquí situamos la importancia 
Enclaves. Revista de Literatura, Música y Artes Escénicas, n. ${ }^{\circ}$ 1, 2021, pp. 6-17. e-ISSN 2792-7350

Inés María Luna, «El idealismo romántico en la cultura flamenca: mito, modernidad y tristeza», https://dx.doi.org/10.12795/enclaves.2021.101.02

del Concurso de Cante Jondo de 1922. El flamenco se convierte de nuevo en salvaguarda de la cultura popular, en expresión de un arte libre, como pone de relieve el deseo de alejamiento de los escenarios, de la realidad profesional, y la voluntad de alejamiento de este género llamado «cuplé», que Lorca considera de manera explícita como expresión absoluta de decadencia. Continúa el camino de estilización de la copla flamenca en virtud de la tristeza, una tristeza que se expresa plenamente en la seguiriya gitana y que será el punto de partida de un proceso extraordinario de renovación estética. Como es sabido, con el magisterio de Manuel de Falla, Lorca establece una distinción entre cante flamenco y cante jondo, este último de origen ancestral, que, aunque no responde a una realidad histórica, supone para el flamenco la creación de un espacio universal y atemporal (Maurer 47), un espacio mítico como consecuencia máxima de este proceso de idealización.

Aunque sus reflexiones sobre el flamenco y sobre nuestra cultura presentan una riqueza extraordinaria, destacamos en este trabajo especialmente la continuidad con una concepción del flamenco que nace a finales del XIX, una concepción espiritual y trascendente del arte que hay que contemplar no solo desde la óptica de la realidad flamenca, sino desde una dimensión cultural mucho más amplia. En este sentido, es muy pertinente el carácter universal que otorga a la cultura española sobre todo en Juego y teoría del duende. La insistencia del flamenco en el dolor y la muerte como algo propio no es ajena a la voluntad de irracionalismo que presenta el arte moderno. Se crea un amplio espacio de dolor donde conviven, junto a la expresión flamenca, Goya, Zurbarán, Nietzsche o San Juan de la Cruz. Nos interesa poner de relieve la concepción del flamenco como arte universal y sobre todo la unión esencial con una tradición española de la tristeza. Son aspectos de gran relevancia no solo en la creación de una estética del flamenco, sino también en la insistencia en una determinada mirada respecto a la cultura española. El flamenco se nos muestra en el hilo de una tradición, y nuestra tradición cultural se contempla desde una tristeza aún más acentuada. De acuerdo con García, «Lorca andaluciza [sic] a España cuando, a partir de la Andalucía del llanto o de la pena negra, del cante jondo y del duende, la convierte en el país de la muerte» (15).

Se une de nuevo la tristeza a la idealización del gitanismo, muy presente en sus reflexiones teóricas y de enorme trascendencia en su creación literaria. El mito del gitanismo, fraguado inicialmente por Demófilo, aunque Lorca no mencionara su obra, cobra matices nuevos y se configura de manera definitiva. El gitano no se separa del andaluz, como sí ocurría en Demófilo y en los autores anteriores. El gitano es el andaluz que cobra una dimensión trágica y universal. Se radicaliza la concepción del mito hasta convertirse en «el eterno desahuciado que canta un polo». ${ }^{4}$ Con esta concepción del gitano como expresión del desamparo, desde el Romancero gitano a Arquitectura del cante jondo, Lorca otorga a la cultura flamenca una dimensión más dilatada. El flamenco se está convirtiendo, como muy bien nos dice Félix Grande, en una estética y en una moral (García Lorca y el flamenco 95). El mito no entra en contradicción con un sentido social y concreto. El gitano presenta una dimensión social exacerbada que trae consigo una concepción social del flamenco, sobre todo a partir de los años treinta. Se trata de una concepción de gran relevancia que se desarrolla en las décadas siguientes: "Ahora, lejos de ser un fenómeno extra-histórico, donde un pueblo "estático" acepta su destino con fatalismo oriental, se insinúa que el cante es un grito de protesta: símbolo de un pueblo — andaluz y gitano - que sufre injustamente frente a la indiferencia de "las clases distinguidas" y de los "señoritos"» (Maurer 94).

\footnotetext{
${ }^{4}$ Fijémonos en la sintonía con «el desharrapado, con la criatura arisca y desgarradora» que, según María Zambrano, cruza toda nuestra cultura (35).
} 
Enclaves. Revista de Literatura, Música y Artes Escénicas, n. ${ }^{\circ}$ 1, 2021, pp. 6-17. e-ISSN 2792-7350

Inés María Luna, «El idealismo romántico en la cultura flamenca: mito, modernidad y tristeza», https://dx.doi.org/10.12795/enclaves.2021.101.02

Es ineludible recordar en este artículo dos libros fundamentales en la creación del ideal flamenco: Andalucía: su comunismo libertario y su cante jondo de Carlos y Pedro Caba, y La copla andaluza de Rafael Cansinos Assens. Destacamos en la primera obra, en sintonía con el pensamiento lorquiano, la importancia de una tradición literaria de la tristeza, una tristeza que forma parte de la condición española y que ha permanecido en la espiritualidad del cante jondo. Con ella sigue ampliándose la concepción humanística del flamenco y este queda unido a la tradición literaria española como una realidad esencial. Afirman Carlos y Pedro Caba: «Es cierto: España es triste... Y lo es a lo largo del tiempo. Lo que quiere decir que no es una tristeza accidental, injertada, embutida en el alma española por una mala política o por un traspié o por un accidente fortuito por ejemplo, sino que es una tristeza de raíces lejanas y profundas [...]» (50). Para Cansinos, la cultura flamenca es expresión por excelencia de una tristeza inmemorial, que se nos presenta, como en la obra de García Lorca, en un espacio impreciso y ambiguo. Se trata de un espacio mítico que sigue engrandeciendo el idealismo de este arte. Hemos de decir, no obstante, que la copla se transmite siempre de manera personal e íntima. Se intensifica el carácter individual y artístico que nos había mostrado Demófilo con un alcance existencial aún más intenso, pues la copla, en su declaración amorosa, viene a manifestar «toda otra razón de más alta tristeza» (53).

Esta concepción idealista no está reñida en los hermanos Caba o en la obra de Cansinos con una autoría individual y moderna. La cultura flamenca es un diálogo continuo entre lo culto y lo popular. La realidad artística del flamenco se desarrolla en los poemas de autor, así como en las representaciones teatrales, porque los poetas continúan este camino de renovación poética a través de la lírica popular. En este sentido, menciona Cansinos la relación de la copla flamenca con los poemas de Bécquer o de Juan Ramón Jiménez, o la conexión con la obra de los Álvarez Quintero, que él separa de una visión exclusivamente costumbrista. También Carlos y Pedro Caba destacan el interés que presentan, a efectos de lo jondo, obras modernas como las comedias de Pascual Guillén y Antonio Quintero y, sobre todo, la obra teatral de los Machado, La Lola se va a los puertos (57). Tampoco existe en ellos una separación radical entre la búsqueda de una cultura idealizada y la realidad profesional de los escenarios. Así, nos expone Cansinos de manera reveladora: «Sin embargo, aun en esas simulaciones preparadas por el genio mercantil de los empresarios, la copla, tras las primeras frialdades, hace obrar la fuerza arrolladora de su fondo atávico, desprende de sí un numen y transfigura a los artistas, arrancándoles su confidencia trágica y convirtiéndolos en voces del destino» (60). No queremos dejar de mencionar que también el Lorca de Arquitectura del cante jondo es muy distinto al autor de la conferencia de 1922. La creación flamenca ya no es la creación anónima del pueblo, sino el fruto del trabajo de unos artistas determinados como Manuel Torre o La Niña de los Peines (Maurer 88).

Es importante destacar que la creación del gitano como héroe trágico se enriquece de manera soberbia con el valor que adquiere en estos autores el mito de lo femenino. Nos referimos a la identificación progresiva de mujer, dolor y cante. El cante se une a la tristeza femenina. Resulta evidente que esta unión no habría sido posible sin el protagonismo que adquiere en el siglo XIX la figura de la heroína trágica. Es Bécquer de nuevo quien inaugura este camino, quien establece una conexión muy significativa entre mujer y melancolía en sus creaciones poéticas y, particularmente, en Cartas literarias a una mujer. Manuel Machado insiste más tarde en el carácter nocturno del cante y en la fatalidad femenina. Con él se recupera en la modernidad, en poemas como «Mariposa negra», «Carmen» o «La ausencia», nuestra canción tradicional de espera femenina (Assumma 365). Se va creando un imaginario en la poesía y en la pintura simbolista que será fundamental en la creación del universo artístico, ya plenamente gitano, de Julio Romero de Torres. 
Enclaves. Revista de Literatura, Música y Artes Escénicas, n. ${ }^{\circ}$ 1, 2021, pp. 6-17. e-ISSN 2792-7350

Inés María Luna, «El idealismo romántico en la cultura flamenca: mito, modernidad y tristeza», https://dx.doi.org/10.12795/enclaves.2021.101.02

No podemos dejar de señalar la relevancia que en este proceso de configuración de un ideal presenta el personaje de «La Lola» de Antonio y Manuel Machado. La cantaora de La Lola se va a los puertos se aleja de los ambientes de marginalidad y flamenquismo gracias al dolor que expresa a través de su cante. De nuevo, la cultura popular puede liberarse a través de la expresión de la tristeza. Es esta vocación de sacrificio la que lleva al personaje a identificarse con una concepción idealista del flamenco. La Lola, como expresión de este ideal, se erige en la representación máxima de mujer y cante. No resulta extraño en un contexto cultural, heredero del modernismo, que exalta el protagonismo femenino y, particularmente, su relación con lo sagrado. Se trata de una dignificación absoluta del cante flamenco que, viniendo de Antonio y Manuel Machado, no resulta, en modo alguno, fortuita (Grande "Lo flamenco en La Lola se va a los puertos" 346). Este universo literario se une plenamente a la identificación lorquiana de la mujer con la pena, una realidad esencial en su obra poética, dramática, así como en sus reflexiones acerca de la cultura flamenca. También Rafael Cansinos Assens en La copla andaluza desarrolla de manera muy reveladora el carácter espiritual y místico de la copla flamenca a través del protagonismo femenino en la obra de Julio Romero de Torres, recreación que tendrá una gran incidencia en las canciones escenificadas de los años cuarenta, sobre todo en las zambras de Manolo Caracol, muy influidas por la estética flamenca.

Esta idealización del gitanismo, fundamental en la cosmovisión moderna de muchos artistas y en su renovación expresiva, también penetra en la configuración estética de otros géneros musicales. Como hemos tratado anteriormente (Luna Flamenco y canción española), a pesar de la voluntad de distanciamiento de la realidad teatral que la cultura flamenca defiende desde el inicio, el flamenco sigue presente en los escenarios. De esta manera, ejerce una gran influencia en la canción orquestada de los años veinte y treinta, y permite que la canción también trascienda la mirada costumbrista, sobre todo con el nacimiento de la zambra. Porque no olvidemos que muchos músicos y letristas, especialmente Rafael de León, están muy relacionados con el flamenco y con una concepción espiritual de la cultura flamenca, en sintonía con los principios del krausismo.

Dichas creaciones de autor se convierten a través del flamenco en una nueva canción de soledad. También para la canción española se recupera una larga tradición de la soledad, importantísima en nuestra literatura, como ya trató el hispanista Karl Vossler. Sin esta influencia musical y poética, no habrían sido posibles creaciones como «Antonio Vargas Heredia» (Mostazo, Merenciano y Oliva), «La Niña de fuego» (León y Quiroga), o «Falsa moneda» (Perelló, Cantabrana y Mostazo). En estos ejemplos, adquiere un carácter muy representativo la conformación del personaje femenino según los presupuestos estéticos modernistas. Nos referimos a la mujer como sombra y amenaza, la mujer rodada tan característica de la copla flamenca, que aparece en ejemplos como «Antonio Vargas Heredia». Pero nos referimos sobre todo a la mujer caída, la mujer que une la tristeza y el pecado, y que nos muestran creaciones como «La Niña de fuego», «María de la O» (Valverde, León y Quiroga), o «La Salvaora» (Quintero, León y Quiroga). La melancolía se funde con la mujer en las representaciones artísticas de finales del XIX. La gitana es la heroína trágica. Así lo demuestran también las creaciones de Rafael de León, muy influidas por la estética flamenca.

\section{Un ideal de arte y vida}

La construcción de un ideal flamenco alcanza un carácter exacerbado a mediados de los años cincuenta y, sobre todo, en los años sesenta y setenta del siglo XX. Ocurre que la creación de esta cultura, que se extiende a lo largo del tiempo, va a estar muy condicionada por las 
Enclaves. Revista de Literatura, Música y Artes Escénicas, n. ${ }^{\circ}$ 1, 2021, pp. 6-17. e-ISSN 2792-7350

Inés María Luna, «El idealismo romántico en la cultura flamenca: mito, modernidad y tristeza», https://dx.doi.org/10.12795/enclaves.2021.101.02

circunstancias políticas y sociales que se viven en España. Es imprescindible tener en cuenta la degradación que está sufriendo la cultura popular y, especialmente, las manifestaciones de la cultura andaluza. En estos años, sobre todo a través del cine y de los espectáculos folclóricos, encontramos una reiteración constante de motivos andaluces y una mezcla indiscriminada de canción y cante. Es decir, existe una unión de flamenco y canción española, como venía ocurriendo desde los años treinta, pero ahora no desde la tristeza y desde el ideal flamenco modernista, sino desde el pintoresquismo y los estereotipos costumbristas más elementales. Se rompe este maridaje de flamenco y canción española que había sido muy fructífero en la música y en la cultura de los años treinta, e incluso en algunas manifestaciones artísticas de los años cuarenta.

En relación con lo que decimos, no puede asombrarnos que surja una corriente intelectual que propugna desde el flamenco el nacimiento de una nueva cultura. Como búsqueda de una verdadera expresión andaluza, tiene lugar un movimiento de reivindicación del flamenco que trae consigo el mayor distanciamiento de la cultura teatral que ha ocurrido hasta la época. Este se consolida artísticamente en cuanto se opone a las formas teatrales y a la cultura profesional. Mientras que la canción española se convierte desde la óptica flamenca en un género trivial y de consumo, se intensifica el valor del flamenco como expresión de desamparo existencial.

Esta creación de una cultura idealizada, que ya tiene un largo recorrido, continúa en los años cincuenta con la obra Flamencología de Anselmo González Climent. No consideramos aquí si tal ensayo describe de manera certera la realidad artística del flamenco, sino su contribución a la progresiva creación de un ideal que tiene su inicio a finales del XIX, y que abre una senda importantísima en la dignificación de la cultura flamenca y en la renovación del arte y de la cultura. Nos interesa esta obra en cuanto insistencia en un acercamiento existencial al cante y en cuanto enriquecimiento de una concepción humanística, en clara sintonía con esta reivindicación de la cultura popular que se viene realizando desde la obra de Demófilo. Nos interesa también como reivindicación sistemática de un ideal flamenco creado de nuevo desde la oposición a la cultura teatral y a la canción orquestada. Ahora con más auge que nunca, se convierte el cante en salvaguarda de la cultura popular.

Encontramos una predisposición filosófica del flamenco, o de la idea del flamenco, que va a provocar el nacimiento de una obra ensayística de gran relevancia en la cultura de estos años. Me refiero a Mundos y formas del cante flamenco de Ricardo Molina y Antonio Mairena, Memoria del flamenco de Félix Grande, a Luces y sombras del flamenco de José Manuel Caballero Bonald o a Esa angustia llamada Andalucía de Luis Rosales, entre otras obras fundamentales. Con ellos, el cante se convierte de manera absoluta en expresión ética y existencial. Se abre el camino para la renovación de la poesía española y para una nueva concepción de la cultura. Sin estas obras que engrandecen su carácter social y existencial, no habría sido posible la renovación poética, teatral o cinematográfica que se lleva a cabo en estos años desde la perspectiva del flamenco, o la dimensión política que este adquiere especialmente en los años setenta.

Como ha ocurrido en otros momentos decisivos, este camino se realiza de nuevo desde la idealización del gitanismo, unida ahora más que nunca al carácter sagrado del cante, y desde la reivindicación de los estilos más relacionados con la sobriedad y el dramatismo. Comienza una voluntad de liberación que conduce a la expresión flamenca, a la búsqueda de sus raíces esenciales. Debido a esta labor, a las letras que se cantan, a la sobriedad de los cantaores, a una brillante teorización sobre el cante, se actualiza la manera de sentir el flamenco. Se trata, como es sabido, de una visión que resulta parcial e idealizada, que acude de nuevo a la construcción mítica, que agudiza de manera dogmática las diferencias entre 
Enclaves. Revista de Literatura, Música y Artes Escénicas, n. ${ }^{\circ}$ 1, 2021, pp. 6-17. e-ISSN 2792-7350

Inés María Luna, «El idealismo romántico en la cultura flamenca: mito, modernidad y tristeza», https://dx.doi.org/10.12795/enclaves.2021.101.02

flamenco y canción española, pero que tiene una gran relevancia en la consolidación del flamenco como realidad estética y en la construcción de una filosofía existencial que, sin duda, va a generar toda una revolución social y artística.

Destacamos la creación de un ideal humanístico que trasciende la realidad musical del flamenco y se convierte en regenerador del arte y de la cultura. La insistencia del flamenco en una expresión constante de intimidad facilita el nacimiento de una nueva concepción estética. Me refiero a la importancia que esta cultura flamenca ejerce en la renovación del lenguaje poético (Félix Grande, José Manuel Caballero Bonald, José Ángel Valente, los poetas de Cántico) y en la renovación del lenguaje teatral o cinematográfico. Es el vehículo idóneo para la expresión del desamparo y alcanza un gran valor estilístico en distintas manifestaciones artísticas. Como custodia de la cultura popular, muestra una gran incidencia en la creación de nuevos parámetros estéticos, acordes con el carácter existencial, pero también social y político que adoptan las disciplinas artísticas de la época. Así lo pone de relieve Ceccherini en el cine y en el teatro de los años sesenta y setenta. Recuérdense, entre otras obras fundamentales, películas como Los flamencos de Jesús Yagüe, donde la profundidad comunicativa del cante se une de manera íntima a la expresión de la soledad y el desarraigo, o la relevancia social y estética que muestra el flamenco en la obra dramática de Alfonso Jiménez Romero. Del mismo modo, este nuevo teatro y esta nueva cinematografía contribuye a la continuidad y a la universalidad de un humanismo de calado flamenco que nace a finales del XIX, y que ahora en estos años alcanza su máxima expresión.

No hay que dejar de lado la importancia que este movimiento intelectual tiene en el pueblo, en la afición flamenca, en unos tiempos en que urge una nueva concepción del arte y una nueva concepción de la cultura. El flamenco se va a convertir para estos hombres en «ese ideal de humanidad para la vida» con el que soñaba la filosofía krausista. Hambrientos de vida y de cultura, encuentran en la expresión flamenca un estímulo vital, un consuelo y un fundamento para sus vidas. La afición flamenca se convierte en élite, con esa concepción aristocrática de la cultura que no significa distanciamiento, sino reivindicación de la dignidad de la expresión popular. Se hace realidad la voluntad demofiliana de separación de la cultura de masas en busca de una verdadera cultura en consonancia con el espíritu de disidencia que tiene el flamenco desde los orígenes. En este contexto, como analiza Martín, situamos la relevante labor artística y social de Francisco Moreno Galván en La Puebla de Cazalla, o el liderazgo espiritual de Diego del Gastor en Morón de la Frontera, alrededor del cual se gesta todo un movimiento de bohemia cultural, con la defensa constante de una nueva vida y con la búsqueda en el arte de una «filosofía del sentimiento», que tiene en los años setenta una trascendencia musical, cultural y política (Vázquez).

Ocurre, además, que la afición flamenca se encuentra con unos cantaores diferentes. Se encuentra con unos cantaores muy alejados de los ámbitos teatrales que pertenecen a otras tradiciones, que están relacionados con los ámbitos familiares y con la cultura de tradición oral, es decir, con cantaores no profesionales que representan fielmente los valores del ideal flamenco. Con ellos, la afición va a recuperar el carácter ritual, comunitario y festivo de este arte. Se resucita un anhelo de hermandad y de libertad. Es muy importante, en este sentido, la labor de rescate cultural que se realiza en la época, como la labor que lleva a cabo José Manuel Caballero Bonald. Se recupera a artistas que representan esta unión de arte y vida que defiende la literatura flamenca desde los tiempos de Demófilo. Nos referimos a Juan Talega, Manolito de María, Fernanda y Bernarda de Utrera, Perrate, Joselero o Rosalía de Triana.

Resulta curioso, sin embargo, que, a pesar de que el ideal flamenco crece desde el inicio en virtud de su oposición a la canción española, una realidad que se muestra con gran insistencia en la literatura flamenca de estos años, también estos cantaores, tan reivindicados 


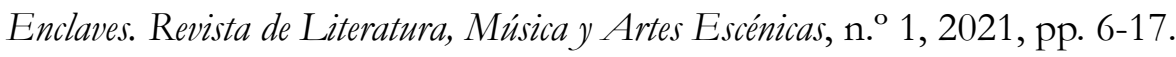
e-ISSN 2792-7350

Inés María Luna, «El idealismo romántico en la cultura flamenca: mito, modernidad y tristeza», https://dx.doi.org/10.12795/enclaves.2021.i01.02

por la nueva crítica, pertenecientes a otras tradiciones y muy alejados de los espacios teatrales, van a seguir cultivando dicho género, aunque con interpretaciones muy distintas y en sintonía con los nuevos contextos del flamenco. Recordemos que en sus interpretaciones las letras se fragmentan de manera absoluta, se difunden en variantes y aparecen registradas por primera vez como coplas populares. Ya no hay conciencia alguna de autoría. Las canciones de Rafael de León se unen a la copla flamenca y se muestran como bulerías pertenecientes a una tradición oral.

De esta manera, con versiones muy libres y sin orquesta, en contextos muy diferentes a los habituales, en el ámbito de la fiesta y de las reuniones íntimas, la canción española se transforma definitivamente a través del flamenco en expresión popular y culmina un camino que se iniciaba en los años treinta con Pastora Pavón y Manuel Vallejo. El flamenco descubre el valor de la canción española como expresión de una memoria compartida. Así nos lo demuestran algunas grabaciones caseras realizadas en Morón de la Frontera en los años setenta. ${ }^{5}$ Recordemos «Madrina», «Amante de abril y mayo», «Tientos del reloj», o «Candela, la de las Minas», creaciones de Quintero, León y Quiroga, en las voces de cantaores de Lebrija y Utrera tan significativos como Perrate, Fernanda y Bernarda, Pepa de Benito o Gaspar de Utrera. Gracias a estas interpretaciones, que desnudan a la canción de todo elemento casticista, se intensifica de manera sobresaliente el carácter existencial de la canción española.

\section{Conclusiones}

El flamenco, como manifestación artística vinculada a determinados entornos culturales y profesionales, no puede separarse de la literatura que lo acompaña desde su nacimiento, que ha inclinado su estética hacia un carácter íntimo y existencial. Esta literatura, que se origina en el contexto del idealismo romántico y en el descubrimiento de lo popular, presenta desde el inicio la voluntad de una cultura idealizada en torno a la expresión de la tristeza y a la idealización del gitanismo, una estilización que ha sido trascendental no solo en la evolución estética del flamenco, sino también en el desarrollo de una dimensión existencial de nuestra cultura. No debe olvidarse que este idealismo romántico se unirá a una importante tradición española de la tristeza, muy presente en los primeros escritos de la historiografía flamenca.

El Romanticismo no es solo un movimiento estético. Es el nacimiento de la modernidad en el arte, una voluntad de libertad y de creación de un arte para la vida. Sin esta vinculación con el idealismo romántico, no habría sido posible el propósito de un arte libre y esta voluntad de custodia de la cultura popular que encontramos en los momentos fundamentales de configuración del flamenco. Así, su estética la conforman unos artistas que reivindican un ideal de arte libre, que viven en un contexto de crisis del arte en la modernidad, artistas como Demófilo y los folcloristas sevillanos de finales del XIX, como García Lorca y el entorno cultural de la Generación del 27, como los poetas de los años cincuenta y sesenta, que, a este desarraigo universal, deben unir las circunstancias sociales de desarraigo que se viven en España. En este contexto tan particular, el flamenco adquiere un carácter político muy destacado.

No es necesario insistir en la importancia que tiene la expresión flamenca en la renovación del arte y de la cultura del siglo XX, en la creación de unos parámetros estéticos que van a influir en la música, la pintura, la literatura o el cine del pasado siglo; en la poesía de Gustavo Adolfo Bécquer, Juan Ramón Jiménez, Manuel Machado o Federico García

\footnotetext{
${ }^{5}$ Algunas de estas grabaciones han quedado registradas posteriormente, como podemos ver en Acal.
} 
Enclaves. Revista de Literatura, Música y Artes Escénicas, n. ${ }^{\circ}$ 1, 2021, pp. 6-17. e-ISSN 2792-7350

Inés María Luna, «El idealismo romántico en la cultura flamenca: mito, modernidad y tristeza», https://dx.doi.org/10.12795/enclaves.2021.i01.02

Lorca; en la renovación poética de los años cincuenta y sesenta; en la pintura simbolista de principios del siglo XX; o en la revolución teatral y cinematográfica de los años sesenta. No debe olvidarse que también permite el nacimiento de una nueva canción española, un género ligado a la escena y a la cultura comercial que se libera de su carácter costumbrista gracias al flamenco. A partir de esta reivindicación constante de un ideal, a partir de este «humanismo de signo andaluz» (393), como lo describe Penna, ha sido posible que una gran revolución humanista se haya proyectado en distintas disciplinas artísticas, lo que ha contribuido aún más a enriquecer el idealismo flamenco.

\section{Referencias}

Acal, Manuel. (Ed.). Cantes inéditos de Fernanda y Bernarda de Utrera. Sevilla: Área de Cultura de la Diputación, 1990.

Andrés, Ramón. Filosofía y consuelo de la música. Barcelona: Acantilado, 2020.

Assumma, María Cristina. Rosa de papel. Una contrahistoria de la literatura española. Madrid: Visor, 2013.

Bartra, Roger. Melancolía y cultura. Las enfermedades del alma en la España del Siglo de Oro. Segunda edición. Barcelona: Anagrama, 2021.

Bolaños, María. "Tiempos de melancolía." Tiempos de melancolía. Creación y desengaño en la España del Siglo de Oro. Madrid: Obra Social de la Caixa, 2015, pp. 15-33.

Caba, Carlos y Pedro Caba (1933). Andalucía, su comunismo libertario y su cante jondo. Prólogo y epílogo de Rubén Caba. Sevilla: Renacimiento, 2008.

Cansinos Assens, Rafael (1933). La copla andaluza. Introducción de Abelardo Linares. Madrid: Arca Ediciones, 2011.

Ceccherini, Francesca. Flamenco y compromiso social en el cine y en las artes escénicas durante los últimos años del franquismo (1960-1975). Tesis Doctoral dirigida por Francisco Perujo y Marco de Marinis. Universidad de Sevilla-Universidad de Bolonia, 2015.

Fubini, Enrico. El Romanticismo: entre música y filosofía. Valencia: Universidad de Valencia, 1999.

García, Miguel Ángel. Melancolía vertebrada. La tristeza andaluza del modernismo a la vanguardia. Barcelona: Anthropos, 2012.

Grande, Félix. "Lo flamenco en La Lola se va a los puertos." Boletín de la Real Academia Sevillana de Buenas Letras: Minervae Baeticae, n. ${ }^{\circ}$ 38, 2010, pp. 341-370.

Grande, Félix. García Lorca y el flamenco. Madrid: Mondadori, 2012.

Luna, Inés María. "El flamenco como expresión de lo sublime: la Colección de cantes flamencos de Antonio Machado y Álvarez." Las fronteras entre los géneros: Flamenco y otras músicas de tradición oral. Actas del III Congreso de Investigación y flamenco, edición de José Miguel Díaz, Francisco Javier Escobar e Inmaculada Ventura. Sevilla: Universidad de Sevilla, 2012, pp. 97-104.

Luna, Inés María. Flamenco y canción española. Sevilla: Universidad de Sevilla, Colección Flamenco, 2019.

Martín, Juan Diego. Estética de lo jondo. Poesía y pintura de Francisco Moreno Galván. Sevilla: Universidad de Sevilla, Colección Flamenco, 2018.

Maurer, Christopher. Lorca y su «Arquitectura del cante jondo». Albolote: Comares, 2000.

Mendonça, Luciana F. M. 'O fado e 'as regras da arte': 'autenticidade', 'pureza' e mercado." Sociologia. Revista da Faculdade de Letras, n. ${ }^{\circ}$ 23, 2012, pp. 71-86. 
Enclaves. Revista de Literatura, Música y Artes Escénicas, n. ${ }^{\circ}$ 1, 2021, pp. 6-17. e-ISSN 2792-7350

Inés María Luna, «El idealismo romántico en la cultura flamenca: mito, modernidad y tristeza», https://dx.doi.org/10.12795/enclaves.2021.i01.02

Penna, Mario. El flamenco y los flamencos. Historia de los gitanos españoles y su música. Edición, traducción y notas de Antonio Zoido. Sevilla: Portada Editorial, 1996.

Pujante, David. Oráculo de tristezas. La melancolía en su historia cultural. Prólogo de José María Álvarez y Fernando Colina. Madrid: Pensódromo, 2018.

Steingress, Gerhard. Sociología del cante flamenco. Sevilla: Signatura, 2005.

Turina, Joaquín. La música andaluza. Introducción de Manuel Castillo. Sevilla: Alfar, 1982.

Vázquez, Pedro Luis. La época dorada del flamenco en Morón de la Frontera (1960-1970). Sevilla: Diputación de Sevilla y Fundación Fernando Villalón, 2016.

Zambrano, María (1939). Pensamiento y poesía en la vida española. Madrid: Endymion, 1996. 